This article constitutes a case study of the development and implementation of the "results framework," an innovative planning and evaluation tool that is rapidly becoming a standard requirement for United States Agency for International Development (USAID) projects. The framework is used in a USAID-funded regional initiative for HIVIAIDS prevention in Central America. This new program evaluation and monitoring tool provides many advantages over traditional evaluation approaches that use outside consultants to provide midterm and end-ofproject evaluations. The results-framework process, which spans the life of the project, provides an opportunity for program staff, donors, partners, and evaluators to work as a team to collect and use rich, longitudinal data for project planning, implementation, and evaluation purposes.

\title{
THE RESULTS FRAMEWORK- AN INNOVATIVE TOOL FOR PROGRAM PLANNING AND EVALUATION
}

\author{
MELISSA M. TOFFOLON-WEISS \\ JANE T. BERTRAND \\ Tulane University \\ STANLEY S. TERRELL \\ United States Agency for International Development
}

The Government Performance and Results Act of 1993 (GPRA) paved the way for the development of the results framework, a monitoring and evaluation tool that has become a standard requirement for United States Agency for International Development (USAID) projects. The United States Congress passed the GPRA in response to persistent reports of waste and inefficiency in governmental agencies. These problems stemmed from inadequate program goals and insufficient program performance monitoring. The main objectives of the bill include holding federal agencies accountable for achieving measurable results, improving service delivery, focusing on service quality and customer satisfaction, and providing Congress with sufficient information on project effectiveness to improve their decision-making capabilities (U.S. Congress 1993). The passage of the bill has initiated sweeping changes in many government agencies including USAID. Through the reengineering process, USAID has adopted a strategic-framework 
approach to track the agency's performance (USAID Center for Development Information and Evaluation 1996). A direct extension of this monitoring approach is the development of the results framework as a program planning and evaluation tool for USAID funded projects.

In 1995, USAID/Guatemala-Central American Program (G-CAP) launched a regional initiative for HIV/AIDS prevention. The onset of the activity coincided with USAID reengineering, and the program staff adopted the results-framework approach for monitoring and evaluation. Since then, the results framework has become almost universal within USAID as a means of monitoring and evaluating programs and initiatives. Due to the newness of this approach, there is a paucity of information in the literature regarding its successes and failures as a planning and evaluation tool.

In this article, we will present a case study of the results-framework approach and illustrate how this approach affects the design, implementation, and evaluation of a regional HIV/AIDS prevention program. Due to the rapid development of HIV/AIDS prevention programs in response to the growing epidemic, many researchers feel that the evaluation of these programs has been hasty and inadequate (Mertens et al. 1994; Wellings 1994). Mertens et al. (1994) stress the importance of systematic and early evaluation to determine if activities are achieving results and are appropriately and effectively implemented. Furthermore, Mertens and Carael (1997) suggest that evaluation must be integrated into program planning. They recommend that all program stakeholders be involved at every stage of the evaluation to create a sense of ownership and ensure that the evaluation meets the needs of the donors, project, and community. USAID has incorporated many of these recommendations into its new evaluation strategy (USAID Center for Development Information and Evaluation 1997). The results framework provides a systematic approach for evaluation that begins early and involves all the constituencies of the program.

\section{THE USAID RESULTS FRAMEWORK}

As part of the results-framework evaluation process, program staff are required to identify the activity's programmatic hypothesis and define the ultimate program objective, generally at the population level. Using the framework, staff must trace the pathways of intermediary and lower level results that will contribute directly to accomplishing this objective. This approach differs from previous monitoring instruments, such as the Program Logical Framework (log-frame), in that it encourages staff to emphasize 
causal linkages of differing levels of importance and focus on concrete results to be achieved, not just activities to be accomplished. Staff are required to continuously monitor program activities for midstream corrections, as well as comprehensively assess change over time on key outcome variables.

Program staff must identify a strategic objective (SO) for the framework that represents the final population level goal that the program seeks to accomplish within a given time frame. Thus, the $\mathrm{SO}$, which is targeted at the ultimate customer, drives the entire program. The intermediate results represent changes that are essential conditions for the achievement of the SO (see Figure 1). USAID monitors progress on these upper level results in its annual reporting, review, and results request (R4) process. Poor performance at this level could negatively affect the continued funding of the program.

Although the strategic objective and intermediate results are long-term goals, the lower level results represent short-term building blocks that facilitate the achievement of the higher level results. These short-term goals are generally measures of program processes and outputs that provide the basis for the attainment of the desired customer-focused higher level results. The lower level results provide valuable monitoring information on progress toward the attainment of the strategic objective.

Each result must have one or more indicators that are used to measure the attainment of the result. Additionally, program staff must set periodic targets for each indicator (see Table 1). Targets are quantified benchmarks that if attained, would indicate progress toward the achievement of the result.

Although results are arranged in a descending hierarchy beginning with the strategic objective, the illustrated framework does not represent a comprehensive causal pathway. The achievement of the lower level results will contribute to the attainment of the strategic objective. However, there are many external factors that may influence attainment of the higher level results. This is especially true with the strategic objective that represents an evaluation of the project's impact. It would be impossible to track all of the causal factors that affect the strategic objective; therefore, the resultsframework approach focuses on key results that can be influenced by the intervention and will contribute to the desired outcome.

The results framework is a multipurpose planning, management, and evaluation and monitoring tool. The process of developing the results framework and achieving consensus on results and indicators takes place among the donor agency representatives (USAID), program staff, partners, and customers. Both USAID and program staff use the results framework to guide activities aimed at achieving the desired programmatic results. Additionally, program staff use the framework's measurable indicators for continuous 


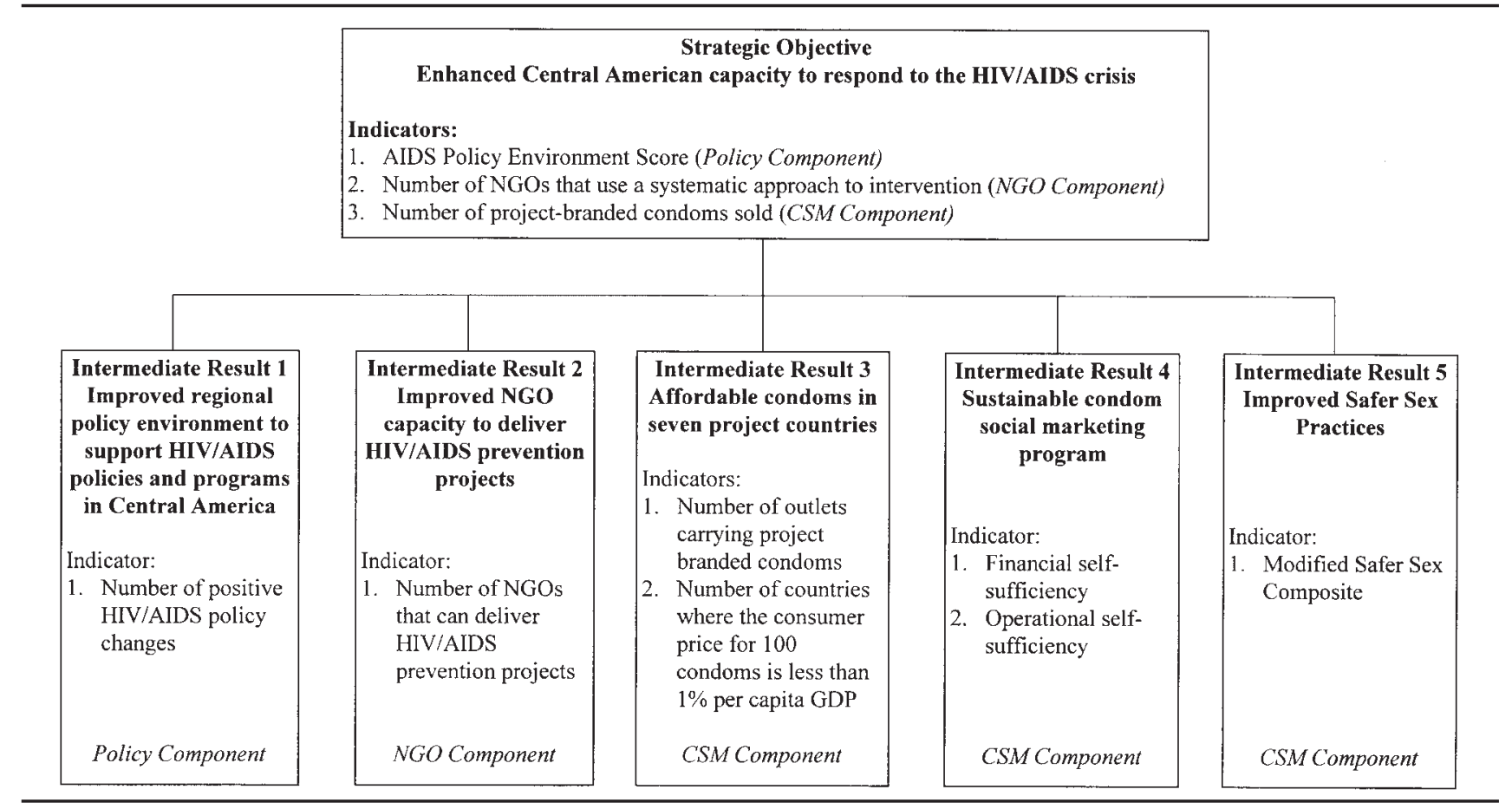

Figure 1: Central American HIV/AIDS Prevention Activity Results Framework-High-Level Results

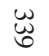

NOTE: $\mathrm{NGO}=$ nongovernmental organization; $\mathrm{CSM}=$ condom social marketing. 
TABLE 1: Description of Strategic Objective Indicator for Policy Component Strategic objective: Enhanced Central American capacity to respond to the HIV crisis Indicator: AIDS Policy Environment Score (AIDS PES)

Source: AIDS PES

Unit: Average of Central American countries' scores

Indicator description: The AIDS PES is an instrument intended to measure the degree to which the policy environment in a particular country supports efforts to prevent the transmission of HIV/AIDS and ensures the rights of people with HIV/AIDS. The tool assesses the following areas of the country's HIV/AIDS policy and program: (a) political support, (b) policy formulation, (c) organizational structure, (d) program resources, (e) evaluation and research, (f) legal and regulatory policies, and $(\mathrm{g})$ program components. Program is defined as a group of interventions that are designed to prevent the transmission of HIV/AIDS. This includes governmentsponsored activities as well as private efforts.

\begin{tabular}{lcc} 
& \multicolumn{2}{c}{ Targets } \\
\cline { 2 - 3 } Year & Planned & Actual \\
\hline 1996 & & 43.8 \\
1997 & - & \\
1998 & 45.5 & \\
1999 & - & \\
2000 & 48.8 & \\
\hline
\end{tabular}

evaluation and monitoring of program activities (USAID Center for Development Information and Evaluation 1996).

The results-framework approach supports USAID's reengineering process that emphasizes four core values: (a) customer focus, (b) managing for results, (c) teamwork, and (d) empowerment-accountability. First, to maintain a customer focus, the strategic objective serves as a guide for the framework and represents the desired benefit for the ultimate customer or the change in host country conditions that affect the ultimate customer. Second, use of the framework encourages program staff to constantly focus on managing for results rather than on process or completion of activities. The U.S. government holds USAID missions and offices accountable for results from their activities and programs. These results, which must be measurable and trackable, are monitored periodically and used to make key programming and resource allocation decisions. Therefore, both USAID and program managers must be concerned with the efficiency and effectiveness of program activities in addition to their mere existence. 
Third, the results-framework development process requires a team effort. The team, which is defined as program staff, USAID representatives, evaluators, customer representatives, and customers, all participate in identifying the anticipated results of the project and designing the steps that must be traversed for the successful realization of these results. The team must develop an evaluation plan and results framework that satisfy the needs of all team members. Thus, the entire team is directly involved in planning and ongoing monitoring of the program. This extensive planning and monitoring process encourages the development of a sense of ownership of the project's activities and achievements among all those involved. Finally, the focus on customerrelated results empowers team members to take action to achieve these results and holds them accountable for what they have achieved.

\section{OVERVIEW OF THE PROJECT}

HIV/AIDS is a growing problem in Central America, driven primarily by the sexual behavior of individuals with multiple sexual partners and fueled by a large reservoir of sexually transmitted diseases. As of December 1997, approximately 1.3 million cases of AIDS had been reported in the Latin American region (UNAIDS 1997). In 1996, the total number of reported AIDS cases in the Central American isthmus was 9,587, with approximately 2,840 deaths resulting from AIDS. Due to underreporting and inadequate surveillance systems in the Central American countries, the actual statistics for AIDS cases are probably substantially higher (FHI-AIDSCAP 1996).

The overall goal of the USAID Central American HIV/AIDS Activity is the "enhanced Central American capacity to respond to the HIV crisis." The activity is focused on strengthening the capabilities of Central American organizations to deliver HIV/AIDS services and information to target groups. Specific activities are organized under three components: (a) policy dialogue/ public awareness, (b) nongovernmental organization (NGO) strengthening, and (c) condom social marketing (CSM).

\section{POLICY DIALOGUE/PUBLIC AWARENESS} AND NGO STRENGTHENING

In September 1995, USAID/G-CAP signed an agreement with a consortium headed by the Academy for Educational Development (AED; 1996) with the Futures Group and International Planned Parenthood Federation/Western Hemisphere Region (IPPF/WHR) for the implementation of the 
policy dialogue/public awareness and NGO strengthening components of the Central American HIV/AIDS Activity. This initiative, named Proyecto Acción SIDA de Centroamerica (PASCA), is being implemented in the following five Central American countries: El Salvador, Guatemala, Honduras, Nicaragua, and Panama.

The policy dialogue/public awareness component supports interventions that will result in improved HIV/STD policies and programs in Central America. Three major activities under this component are

1. supporting regional policy research to strengthen policy formulation through a better understanding of the nature of public awareness and policy development in the region,

2. developing a leadership cadre capable of favorably changing the policy environment for HIV/AIDS prevention, and

3. increasing public awareness and support for effective prevention policies and programs.

The NGO strengthening component provides assistance for an improved NGO capacity to deliver HIV-prevention programs. Major activities under this component are

1. providing technical assistance and training to improve the programmatic and management skills and structures of NGOs that provide HIV/AIDS prevention services,

2. implementing a small-grants program to improve the coverage and quality of services and prevention activities while increasing the long-term local capacity to carry out such programs, and

3. encouraging effective networking and information exchange among NGOs within the region, thereby enhancing programs and promoting supportive policies.

\section{CSM}

The CSM component is focused on creating a sustainable and effective private sector operation to reduce risky sexual behaviors, thereby decreasing the sexual transmission of HIV and other STDs in the region. In September 1996, USAID/G-CAP signed an agreement with Population Services International (PSI) for the implementation of this component in seven Central American countries (Belize, Costa Rica, El Salvador, Guatemala, Honduras, Nicaragua, and Panama). 
Condoms are underused in Central America, due in large part to inappropriate personal risk assessment, insufficient promotion or advertising, and in some cases overpricing. This program attempts to bring the price of condoms into parity with the disposable income of lower income groups in each country. It is anticipated that this pricing adjustment, along with aggressive promotional activities, will expand the overall market for condoms. The program strives to maintain low condom prices while achieving economic sustainability through the income from the sale of cross-subsidy products that have public health benefits (e.g., Pap smear kits, weaning cups, etc.).

\section{EVALUATION}

USAID/G-CAP and program staff agreed early in the implementation phase of the PASCA and Pan-American Social Marketing Organization (PASMO 1997) programs to incorporate monitoring and evaluation activities as an integral program component, rather than as an external auditing activity. While USAID developed the strategic objective during the request for proposal phase, program staff took the lead on the development of the intermediate and lower level results. Evaluators from the EVALUATION Project helped project staff operationalize the results into measurable indicators and assisted with the design of evaluation instruments and methodology. ${ }^{1}$

PASCA staff presented their results framework at the PASCA Review Meeting, held approximately 1 year after the program started. This meeting brought together USAID, PASCA, and EVALUATION Project staff, as well as key partners and customer representatives, to review and finalize the framework. During the final day of the meeting, PASCA and its partners reviewed the framework result by result in an effort to achieve consensus. The USAID Results Package officer frequently referred to the framework throughout the first year as being written in "slow drying cement." The focus of this meeting was to review the framework one last time before the cement hardened.

During the third year of the PASCA program, USAID requested that in place of a traditional midterm evaluation by outside evaluators, the MEASURE Evaluation Project (the follow-on to The EVALUATION Project) conduct a midterm review of PASCA. The review, which was guided by the results framework, was focused on identifying the program's major achievements and challenges in terms of the anticipated results. This included the collection and analysis of results-framework data, along with employing in-depth interviews and surveys to collect feedback on program 
performance from USAID representatives, program staff, partners, and customer representatives. These activities provided valuable feedback on program performance and important recommendations for the final 2 years of the activity.

The third component, a CSM program, was awarded to PSI in September 1996. Subsequently, PSI has developed a results framework for the third component in consultation with EVALUATION Project and USAID staff. In a manner similar to the PASCA program, this framework is being used to guide program planning and implementation.

\section{THE CENTRAL AMERICAN HIV/AIDS PREVENTION ACTIVITY RESULTS FRAMEWORK}

\section{RESULTS AND INDICATORS}

The strategic objective of the PASCA and PASMO initiatives, which are represented in a single results framework, is "enhanced Central American capacity to respond to the HIV/AIDS crisis." While all three components share the same strategic objective, each component has a different indicator that will measure its contribution to the attainment of the objective (see Figure 1). The policy-component strategic objective indicator is the score from the AIDS Policy Environment Score (AIDS PES). The NGO component strategic objective indicator is the number of NGOs that use a systematic approach to intervention. Finally, the progress of the CSM component toward attainment of the strategic objective is being assessed in terms of the number of project-branded condoms sold annually.

The Central American HIV/AIDS Prevention Activity results framework incorporates indicators that have been recommended by the World Health Organization (WHO) for the evaluation of national HIV/AIDS prevention programs along with a number of "experimental" indicators. In 1994, WHO proposed a core set of 10 prevention indicators along with data sources for the evaluation of national prevention programs (Mertens and Carael 1997). The Central American activity team chose to adapt a number of the conventional indicators to meet the needs of the regional project. The team did not include any prevalence indicators due to inadequate STD and HIV surveillance systems in the region and the high cost of conducting these studies. Rather, the activity selected indicators that measure the extent, capacity, and impact of HIV/AIDS prevention activities in the region. The WHO prevention indicators that were included are 
- the number of condoms that are distributed by the activity,

- the number of people who report having a single sexual partner in the last 12 months, and

- the number of people having used a condom in their last sexual act with a nonregular partner (Mertens and Carael 1997).

The policy component portion of the results framework consists of one intermediate result and four lower level results. The intermediate result focuses on improving the regional policy environment to support HIV/AIDS prevention policies and programs in Central America. This result will be measured by assessing the number of positive policy changes that occur in each country. Positive policy changes are defined as changes that are supportive of HIV/AIDS prevention activities and protective of the rights of people with HIV/AIDS. The change could be the addition of a favorable law or regulation, or a deletion or modification of an unfavorable law or regulation. The lower level results describe building blocks that will contribute to the attainment of the intermediate result and, ultimately, the strategic objective. For example, Lower Level Result 1.3 is "more favorable attitudes toward HIV/ AIDS prevention among policy makers and other influentials." This result, which is necessary for the development of positive policy changes, will be measured by the number of newspaper articles published in each country that report supportive policies, actions, and statements for HIV/AIDS prevention activities.

Although the NGO component strategic objective indicator focuses on ensuring that NGOs use a systematic approach to service delivery, the component's intermediate result is targeted at improving the management and administrative capabilities of NGOs. The result, "improved NGO capacity to deliver HIV/AIDS prevention projects," is measured by counting the number of NGOs that meet predetermined management- and financial-sustainability criteria. The NGO component has four lower level results that contribute to the improvement of both the service delivery and the administrative capabilities of the organization.

The CSM component has the following three intermediate results: (a) sustainable CSM program, (b) affordable condoms in seven project countries, and (c) improved safer sex practices. ${ }^{2}$ Indicators for the first two intermediate results include service statistics and accounting information, such as the number of outlets carrying project branded condoms or net revenues divided by operating costs. The third intermediate result indicator is the safer sex composite. This indicator, which is measured with data from the Knowledge, Attitudes, and Practices (KAP) study, is defined as the proportion of a target population that reports abstinence from all penetrative sex (oral, anal, and 
vaginal) over the previous 12 months, or a single sex partner for the previous 12 months, or condom use in the last sexual act with a nonregular partner. There are four lower level results that contribute to the attainment of these intermediate results.

\section{DATA SOURCES}

Six data sources are required for the Central American HIV/AIDS Prevention Activity results framework (see Table 2). Although a number of data sources were developed specifically for this project, other data are being collected from conventional sources that are crucial to the implementation of ongoing activities. For example, the data for indicators that are used to assess the financial sustainability of the CSM component are being collected as a matter of course by the component's management information system. These indicators include operating costs divided by revenues, quick ratio liquidity, average accounts collection period, and the average inventory turnover. The only data sources that have been developed for the results framework that will not also be used for project implementation are the media scan and the CSM KAP Study. The following is a brief description of each data source.

\section{AIDS PES}

The AIDS PES measures the degree to which the policy environment in a particular country supports efforts to prevent the transmission of HIV/AIDS and ensures the rights of people with AIDS. The AIDS PES reflects the current level of support and is used to track changes that take place over a period of time as a result of policy activities of the type conducted or supported by the PASCA project.

The AIDS PES is a self-administered survey with a purposive sample of approximately 20 HIV/AIDS experts in each country (see Table 3). The instrument is administered at the beginning, midpoint, and end of the PASCA project. Every effort is being made to survey the same sample of individuals at each round. However, if a respondent no longer holds the position in question during the subsequent round of data collection, the individual who is currently in the position of the original respondent is selected. The instrument is composed of seven sections with 53 close-ended quantitative questions. The total country score is calculated as the weighted average score for all the questionnaires collected in a particular country. USAID Global Bureau has adopted the AIDS PES as a core indicator for evaluating HIV/AIDS activities (Brown 1998). 
TABLE 2: Data Sources for the Central American HIV/AIDS Prevention Activity Results Framework

\begin{tabular}{|c|c|c|c|c|}
\hline Component & $\begin{array}{l}\text { Data } \\
\text { Source }\end{array}$ & Description & $\begin{array}{l}\text { Frequency of } \\
\text { Data Collection }\end{array}$ & $\begin{array}{l}\text { Sample } \\
\text { Description }\end{array}$ \\
\hline Policy & AIDS PES & $\begin{array}{l}\text { A self-administered survey of HIV/AIDS } \\
\text { experts that is intended to measure the } \\
\text { degree to which the policy environment } \\
\text { in a particular country supports efforts to } \\
\text { prevent the transmission of HIV/AIDS and } \\
\text { ensure the rights of people with AIDS }\end{array}$ & $\begin{array}{l}\text { Beginning, midpoint, } \\
\text { and end of project }\end{array}$ & $\begin{array}{l}\text { Approximately } 100 \\
\text { HIV/AIDS experts in } \\
\text { five project countries } \\
\text { (20 per country) }\end{array}$ \\
\hline Policy & Media scan & $\begin{array}{l}\text { A content analysis of local newspapers in an effort } \\
\text { to evaluate the involvement and attitudes of } \\
\text { leaders from all sectors of society on HIV/AIDS } \\
\text { issues }\end{array}$ & $\begin{array}{l}\text { Ongoing throughout the } \\
\text { life of the project }\end{array}$ & $\begin{array}{l}\text { All articles that relate } \\
\text { to HIV/AIDS in the } \\
\text { major newspapers in } \\
\text { five countries }\end{array}$ \\
\hline Policy & $\begin{array}{l}\text { Legal and } \\
\text { Regulatory } \\
\text { Policy Inventory }\end{array}$ & $\begin{array}{l}\text { A comprehensive review of the legal and regula- } \\
\text { tory framework as it relates to HIV/AIDS }\end{array}$ & $\begin{array}{l}\text { Inventory conducted at } \\
\text { baseline and updated } \\
\text { yearly throughout the } \\
\text { life of the project }\end{array}$ & $\begin{array}{l}\text { Inventories are being } \\
\text { conducted in five } \\
\text { countries }\end{array}$ \\
\hline NGO & $\begin{array}{l}\text { NGO needs } \\
\text { assessment }\end{array}$ & $\begin{array}{l}\text { A self-administered survey to assess the manage- } \\
\text { ment, financial, and programming capacity of } \\
\text { NGOs involved in HIV/AIDS prevention }\end{array}$ & $\begin{array}{l}\text { Beginning, midpoint, } \\
\text { and end of project }\end{array}$ & $\begin{array}{l}91 \text { NGOs in five } \\
\text { countries }\end{array}$ \\
\hline CSM & KAP Study & $\begin{array}{l}\text { A survey that measures change in reported safer } \\
\text { sex practices in relation to the CSM component }\end{array}$ & $\begin{array}{l}\text { Beginning, midpoint, } \\
\text { and end of project }\end{array}$ & $\begin{array}{l}600 \text { individuals from } 3 \\
\text { target groups (com- } \\
\text { mercial sex workers, } \\
\text { men who have sex } \\
\text { with men, youth) in } \\
\text { two countries }\end{array}$ \\
\hline $\begin{array}{l}\text { Policy, } \\
\text { NGO, } \\
\text { CSM }\end{array}$ & $\begin{array}{l}\text { Databases and } \\
\text { program } \\
\text { records }\end{array}$ & $\begin{array}{l}\text { Four databases will be established to monitor project } \\
\text { activities: (a) an evaluation database, (b) a consul- } \\
\text { tant database, (c) a NGO database, and (d) the } \\
\text { PASMO management information system }\end{array}$ & $\begin{array}{l}\text { Ongoing for the life } \\
\text { of the project }\end{array}$ & \\
\hline
\end{tabular}




\section{$\underset{\infty}{\infty}$ TABLE 3: AIDS Policy Environment Score}

Scale

\section{Political support}

Please indicate the level of support that is provided by the following groups for an effective HIV/AIDS

policy and program.

High-level government officials

General public

Main political parties

Top planning bureaucrats

Major religious organizations

Private sector leaders

Nongovernmental organization (NGO) leaders

\section{Policy formulation}

Please read the following statements regarding the HIV/AIDS program and policy in your country.

Circle the number that best expresses your level of agreement with the following statements.

A favorable national policy exists.

Formal program goals exist.

Specific strategies to meet program goals exist.

A functional national coordinating body exists.

Ministries other than the Ministry of Health are involved in policy formulation.

Policy dialogue and formulation involves NGOs, community leaders, and representatives of the private sector and special interest groups.

Organizational structure

Please read the following statements regarding the HIV/AIDS program and policy in your country.

Circle the number that best expresses your level of agreement with the following statements.

The AIDS Control Program (ACP) is placed high in the government structure.

The ACP director is full-time and reports to an influential superior officer. 
Ministries other than the Ministry of Health are involved in program implementation.

The private sector is formally included in the AIDS Control Program.

NGOs are formally included in the AIDS Control Program.

Program resources

Please read the following statements regarding HIV/AIDS program resources and circle the answer

that best reflects your level of agreement or disagreement with each statement.

1 (disagree) to 5 (agree)

Resources are allocated according to priority guidelines.

Current funding can be used flexibly to support effective new programs.

There are technically competent professionals staffing the program.

Adequate technical information is available to professionals and organizations who work in the program.

Please rate the level of financial support for HIV/AIDS programs provided by the following groups.

Ministry of Health

Private sector

International donor community

Social security

Evaluation and research

Please circle the answer that most accurately reflects your level of agreement or

disagreement with each statement.

There is a process established to evaluate the program.

Evaluation and research results are actively employed in policy formulation.

Special studies are undertaken as needed to improve the program.

\section{Legal and regulatory}

Please read the following statements regarding the HIV/AIDS legal and regulatory environment.

Circle the answer that most accurately reflects the current situation in your country.

Condom advertising is allowed.

Antidiscrimination regulations exist.

Mandatory testing exists.

Confidentiality of test results is guaranteed.

$\stackrel{\omega}{b}$ Current regulations encourage the importation of condoms. 
Current regulations encourage the importation of STD drugs.

There are restrictions on condom distribution.

There are unethical AIDS laws (quarantine, incarceration, discrimination).

There is officially condoned harassment of high-risk groups (commercial sex workers,

men who have sex with men, street children).

There is mandatory reporting of HIV test results.

NGO registration procedures are clear, straightforward, and fair.

Restrictions exist on who may receive STD services.

\section{Program components}

Please read the following list of program components and circle the number that best reflects your opinion on the existence and availability of each component in your country.

Guidelines to reduce risk of transmission of HIV to health workers.

An active program component to promote accurate reporting by the media

A functional logistics system for STD drugs

A functional logistics system for condoms

Social marketing activities for condoms

Social marketing activities for STD drugs

National treatment guidelines for STDs

Special prevention activities for high-risk groups

An intervention to make confidential testing and counseling available on demand

Family life education for youth in school

A functional surveillance system 


\section{Legal and Regulatory Policy Inventory}

The Legal and Regulatory Policy Inventory is a comprehensive review of the legal and regulatory framework as it relates to HIV/AIDS in each of the five project countries. It encompasses all aspects related to the planning, financing, and delivery of preventative and therapeutic services. It includes, for example, practices that may have been adopted in the private sector without "official" sanction (e.g., health worker safety guidelines developed by an internal human resource management department). The purpose of the inventory is to identify opportunities for PASCA to support specific reform actions that will result in a favorable HIV/AIDS policy environment.

An inventory has been established for each of the five project countries during the first year of the project. Throughout the project, each country inventory will be updated to reflect changes that have occurred since the baseline inventory. Periodically, a group of HIV/AIDS experts will meet to review the policy inventories, analyze the policy change, and determine the number of changes that have occurred in each of the countries.

\section{Media Scan}

The media scan is a content-analysis study that analyzes information obtained from local newspaper articles in each country in an effort to evaluate the involvement and attitudes of leaders from all sectors of society on HIV/AIDS issues. Articles are selected for the scan if they have the words or acronyms for HIV/AIDS in the title or in the first paragraph. The content analysis examines the activities and statements reported in each article and rates the article's level of support for HIV/AIDS prevention activities, as well as protection of the rights of people with HIV/AIDS.

\section{Institutional Capacity Assessment}

The Institutional Capacity Assessment is a tool that assesses the technical and management capacity of NGOs to respond to the HIV/AIDS situation in Central America. The questionnaire solicits information regarding the organization's prevention activities, target audiences, level of collaboration with other local or regional programs, and management and financial structures and capabilities. The instrument, which includes both closed and openended questions, is administered to the director or highest ranking administrator of the NGO. An organization is included in the sample if it is involved 
in HIV/AIDS prevention activities in one of the five project countries and has a nonprofit status.

Initially, in the first year of the project, the assessment was conducted as a self-administered survey that was delivered by courier to the organization. However, in response to a request from USAID, an onsite study was conducted with a subsample of NGOs to assess the validity of the self-reported data. The study revealed that the self-reported data from the baseline study exaggerated the technical capacity of the NGOs. In response to these findings, the initial study methodology was changed. During the Midproject Review, the assessment was conducted during a site visit and included both a survey and the observation of documents.

PASCA and MEASURE staff created two scales (with questions from the International Cooperative Alliance [ICA]) that are used to evaluate the management and programmatic capabilities of the NGOs. These scales are called the Management and Financial Sustainability Scale (MFSS) and the Systematic Approach Scale (SAS). The MFSS is used to assess the following structures and skills for each NGO: mission, internal structure, human resource management, strategic planning, monitoring and evaluation, financial and accounting structures, and information systems. The organizations are scored on a seven-point scale, based on their reported structures and skills in the seven areas. Each organization with a score of five points or higher is considered capable of independently delivering and supporting interventions (Intermediate Result 2 indicator).

The SAS scale measures the project's utilization of a systematic approach to intervention design and monitoring. Organization staff are asked to identify the theories and approaches that they used to design their primary project. Additionally, organization staff are asked if monitoring and evaluation results contribute to program design and implementation efforts. If an NGO meets the criteria specified in a scale section, they receive one point. NGOs that score three points on the scale are considered to use a systematic approach to intervention. This scale measures the strategic objective indicator: "the number of NGOs that use a systematic approach to interventions."

\section{CSM KAP Study}

The CSM KAP study measures change in safer sex practices in relation to the CSM component. This study targets two groups with high risk for HIV transmission and infection, men who have sex with men and female commercial sex workers (both brothel-based and streetwalkers). Baseline data were collected in Costa Rica, El Salvador, Guatemala, Honduras, Nicaragua, and 
Panama. The capital city was selected in all cases except Honduras, where the highest levels of HIV are found in San Pedro Sula. The survey was designed to measure condom use among these groups at baseline, midproject, and end of project (for the full reports, see Madrigal 1998a and Madrigal 1998b).

\section{Project Records and Databases}

The following three databases have been created by PASCA and PASMO to monitor activities and assist with program implementation: (a) The Consultant Database, (b) The NGO Database, and (c) The PASMO Management Information System. The Consultant Database, housed in a local NGO, contains current information on local and regional HIV/AIDS programming and management consultants who are available to provide training and technical assistance to NGOs and other organizations. The NGO database contains a record of all local and regional NGOs that are currently providing HIV/AIDS prevention activities. As the project progresses, this database will become the responsibility of a local NGO. Additionally, PASMO is maintaining a management information system that collects all of the information that relates to the organization's management, finances, and sales (standard financial indicators used in business and marketing). Finally, each program component maintains relevant records that include information on activities, contracts, distributor agreements, and so on.

\section{PRESENTATION AND REVIEW OF DATA}

Rossi and Freeman (1993) state that it is important for program evaluations to include comprehensive dissemination plans to ensure that all of the involved parties have the opportunity to fully use the information that is collected. The results-framework evaluation data is useful to several constituencies. First, the donor agency, USAID, receives annual feedback on high level results to guarantee that the activity is indeed strengthening HIV/AIDS prevention capabilities in the region. Second, careful measurement of lower level results provides program managers and staff with informative feedback on the effectiveness of PASCA activities. Third, project partners, stakeholders, and customer representatives are provided with relevant evaluation findings at program review meetings.

In the first and third years of the PASCA project, project staff, partners, customer representatives, and stakeholders were all invited to program review meetings. The meetings provided a forum to present the baseline and midterm findings and receive feedback on program strategy, activities, and 
results. Additionally, an interactive results-framework database, which will be available during the second half of the project, allows evaluation findings to be conveniently available to the user on a timely basis. The database provides up-to-date evaluation findings at the fingertips of program managers and donors. The database allows the user to select any result and view or print out a description of the indicators, targets, and current status of result achievement (as seen in Table 1). Additionally, full descriptions of the evaluation instruments are included in the database. The audience for these findings will be expanded in the future to include other researchers, policy makers, and program managers by placing the interactive results-framework database on the Internet.

\section{BENEFITS OF THE RESULTS-FRAMEWORK APPROACH}

In addition to establishing a structured framework for evaluation and timely reporting of findings, the results framework provides a number of benefits not found in traditional program evaluations. These benefits include a constant focus on project results, a team-oriented evaluation approach, and the incorporation of a longitudinal study design.

The use of the results framework ensures that program staff and donor agencies will maintain a constant focus on the main goals that are established early on in the program. Often, during the life of a program, managers and donors are faced with requests for assistance outside the activity's initial scope of work. If staff attempt to address these new areas, crucial resources will be diverted away from the original program mission. When the resultsframework approach is employed, the program manager is cognizant that the entire program evaluation and, potentially, continued funding are dependent on reaching the stated targets. Therefore, there is a strong impetus to maintain the original program goals.

The results-framework evaluation process offers a distinct advantage over a cross-sectional midterm and end-of-project evaluation performed by outside consultants. Evaluators, program staff, managers, and sponsors share in the process of developing the results framework. This team effort creates and maintains a focus on the importance of achieving the agreed-on results. This

process, while logistically difficult, ensures that all actors have a sense of ownership in the results framework and receive evaluation findings that meet their needs. For example, when the coordinator of the NGO strengthening component was recently planning a training workshop on project design, she 
was able to use the evaluation findings from the Institutional Capacity Assessment to identify each organization's deficits and to pinpoint their specific training needs.

The team approach also decreases anxiety levels of program staff surrounding the evaluation. Holosko (1996) and numerous other scholars report that program evaluations precipitate unnecessary anxiety among program staff (Lincoln and Guba 1985; Rossi and Wright 1967; Suchman 1967). He states that evaluations not only include "fault finding" but also provide the opportunity to discover positive findings. The team approach to evaluation used in the results-framework process serves to demystify the evaluation experience. Staff have input into the evaluation process from the start of the project, and they are fully aware of the evaluation criteria that are being used. Furthermore, every effort is made throughout the project to disseminate both positive and negative findings to the staff to constructively influence program implementation.

Another advantage of the results framework over a traditional crosssectional evaluation approach is that the development of midterm and endof-project reports are less energy intensive and stressful for donors, evaluators, and program staff.

Although staff and donors may invest a significant amount of time in the beginning of the program to develop the results framework, the use of the same evaluation team throughout the program makes the development of evaluation reports less labor and time intensive for program staff and donors. Traditionally, it is time consuming to identify, contract, and orient an outside evaluation team to conduct midterm and final project evaluations. Additionally, it is difficult to fully inform an outside evaluation team that has had no previous contact with the program on program activities and results as well as the country context that affects these results. The results-framework approach that was used in this case study employed the same evaluators throughout the life of the activity. Therefore, in the development of midproject and end-of-project evaluation reports, the need for intensive program staff involvement is minimal, and the evaluator's knowledge about the project is extensive.

This long-term evaluation process also allows for the use of a longitudinal study design for overall evaluation, as well as periodic special studies that take place as part of the evaluation. A strength of this design is that it requires data for all framework indicators that can be used to compare preproject and postproject conditions. For example, the AIDS PES is an instrument that assesses the policy environment for HIV/AIDS prevention in each country. Prior to the start of project activities, this survey was administered to 20 HIV/AIDS experts in each country in an effort to establish a baseline score 
for the regional policy environment. Each country was assigned a score on a total scale of 100 points. This score will be compared to midproject and endof-project scores to measure change over the life of the project.

\section{LIMITATIONS OF THE RESULTS-FRAMEWORK APPROACH}

The major limitation of the results-framework approach is that it attempts to synthesize very complex development processes into quantifiable indicators that may or may not fully capture achievements and progress. It may be apparent that the chosen results do not reflect all the factors that affect the anticipated final outcome and, in fact, may ignore the most important ones. For example, a key factor that is not included in the results for the NGO component is the level of international funding available to Central American NGOs. If available funding levels dramatically decline due to an unexpected economic or political crisis, the capacity of NGOs to deliver HIV/AIDS prevention projects would be severely impaired.

Another limitation is that although the framework may serve USAID's needs, it may not fully meet the program's monitoring needs. For example, PASMO supplies USAID with the appropriate results-framework data but collects additional financial indicators (e.g., pertaining to the profitability of cross-subsidy products) that are needed to ensure the viability of the project.

One also has to guard against the possibility of the evaluation process leading the project. Project staff may be reluctant to engage in important development activities because these activities do not affect the indicators in the framework. To minimize this limitation, donor agency officials at all levels need to be sensitive to the potential deficiencies of this approach and open to the addition of contextual information to enrich the evaluation process.

Another potential source of bias is the involvement of program staff in the evaluation process. Clearly, program staff would prefer to have a favorable evaluation of the project. Thus, they will be highly motivated to collect evaluation data that reflect positively on the activity and, perhaps, downplay any information that identifies weaknesses. It is important that evaluators adequately supervise the monitoring process and guard against this source of bias.

A final limitation of this approach is the potential loss of evaluator subjectivity due to the long-term working relationship between the evaluation team 
and project staff. This may be unavoidable as relationships form and the political culture of the organization grows to include the evaluator. Evaluators working in the field are always faced with tough choices between trying to maintain ideal research conditions and designing affordable and feasible evaluations. The existence of a long-term relationship between project staff and evaluators increases the likelihood that identifying too closely with project-related issues may influence the evaluator's assessment.

\section{CONCLUSION}

The results framework is a relatively new USAID monitoring and evaluation approach. Use of this program planning and evaluation tool provides numerous benefits to donors, program staff, and evaluators. First, due to the strong emphasis on results, staff and donors maintain a constant focus on the results (output) of the program as opposed to activities (process). This provides a strong incentive to preserve the original project goals. Second, the "team-oriented" aspect of this approach facilitates the active involvement of program staff, donors, evaluators, and customers. This involvement improves the chances that evaluation results will be employed during the life of the program to assist with program implementation. Third, because the initiation of the evaluation process coincides with the start of the project, there is an emphasis on the collection of rich longitudinal data starting with baseline data for all framework indicators. Finally, the involvement of the same evaluation team throughout the life of the project facilitates a comprehensive evaluation that is less labor intensive for the program staff and donor during the midterm and end-of-project evaluation periods. Although none of these benefits are necessarily novel, the approach provides distinct advantages over traditional evaluation strategies that use cross-sectional midterm and end-of-project evaluations.

In future projects, it would be useful to measure the amount of resources (e.g., staff time, finances) that are required for this new evaluation approach, as compared to other approaches. Additionally, it will be important to assess the quality of the evaluation studies in the context of a larger sample of projects that use the results framework. Although the results framework is a relatively new evaluation approach for international development initiatives, the early observations of the use of this tool that are presented in this case study are encouraging. 


\section{NOTES}

1. A United States Agency for International Development-funded project is responsible for providing technical assistance to this monitoring activity.

2. Pan-American Social Marketing Organization targets seven countries-the same countries as Proyecto Acción SIDA de Centroamerica, plus Belize and Costa Rica.

\section{REFERENCES}

Academy for Educational Development. 1996. Central American HIV/AIDS Prevention Project. Washington, DC: Academy for Educational Development.

Brown, L. 1998. Handbook of indicators for USAID/AIDS/STD Programs. (Unpublished report) MEASURE Evaluation Project, Tulane University, New Orleans, LA.

Holosko, M. J., 1996. Obstacles to conducting program evaluations: Implications for public health evaluators. Journal of Health \& Social Policy 8:91-101.

Lincoln, Y. S., and E. Guba. 1985. Naturalistic inquiry. Newbury Park, CA: Sage.

Madrigal, J. P. 1998a. El condon y las trabajadores comerciales del sexo: Encuesta en America Central. (Unpublished editorial ILPES)

Madrigal, J. P. 1998b. El condon y los hombres que tienen sexo con hombres. (Unpublished editorial ILPES)

Mertens, E. T., and M. Carael. 1997. Evaluation of HIV/STD prevention, care and support: An update on who's approaches. AIDS Education and Prevention 9 (2): 133-45.

Mertens, T., M. Carael, P. Sato, J. Cleland, H. Ward, and G. D. Smith. 1994. Prevention Indicators for Evaluating the Progress of National AIDS Programmes. AIDS 8 (10): 1359-69.

Panamerican Social Marketing Organization. 1997. PASMO proposal-Executive summary. Panamerican Social Marketing Organization.

Rossi, Peter, and Howard Freeman. 1993. Evaluation, a systematic approach. Newbury Park, CA: Sage.

Rossi, P., and S. Wright. 1967. Evaluation research: An assessment of theory, practice, and politics. Evaluation Quarterly 1 (1): 5-52.

Senate and House of Representatives of the United States Congress. 1993. Government and Performance Act of 1993. Washington, DC: U.S. Government Printing Office.

Suchman, E. 1967. Evaluative Research. New York: Russel Sage.

United States Agency for International Development, Center for Development Information and Evaluation. 1997. Performance monitoring and evaluation tips. Washington, DC: US Agency for International Development.

United States Agency for International Development, Center for Development Information and Evaluation, Bureau for Policy and Program Planning. 1996. Resource book on strategic planning and performance monitoring under reengineering. Washington, DC: US Agency for International Development.

United States Agency for International Development, Guatemala-Central American Projects. 1996. Program Description Central American HIV/AIDS Prevention Project. Washington, DC: US Agency for International Development. 
Wellings, K. 1994. Assessing AIDS prevention strategies in Europe: Lessons for evaluative research. In Evaluating AIDS prevention programs, edited by National Research Council. Washington, DC: National Academy Press.

Melissa M. Toffolon-Weiss, M.P.H., is a doctoral student in the Department of Sociology at Tulane University. For the past 2 years, she has worked for the MEASURE Evaluation Project, conducting monitoring and evaluation activities in Central America. She is currently conducting research on environmental justice issues in Louisiana.

Jane T. Bertrand, Ph.D. (sociology), is a professor and the chair of the Department of International Health and Development, Tulane University, School of Public Health and Tropical Medicine. She has worked since 1991 on monitoring and evaluation issues under the USAID-funded contract for The EVALUATION Project and its successor the MEASURE Evaluation Project. In addition, she has published extensively on issues of family planning and reproductive health in Guatemala.

Stanley S. Terrell, Ph.D., graduated from Tulane University with a doctoral degree in public health. He has worked in Central America for 9 years directing public health projects. He is currently a technical advisor in AIDS and child survival at the United States Agency for International Development/Guatemala-Central American Programs. 